\title{
Application of Multi Composite Programming and Promethee for the Analysis of the Wastewater Treatment Plant Efficiency
}

\author{
Bojan Đurin 1,*, Atena Pezeshki ${ }^{2}$, Sara Dadar ${ }^{2}$, Lucija Plantak ${ }^{3}$, Damira Keček ${ }^{4}$, Nikola Kranjčićc ${ }^{3}$ \\ 1 University North, Department of Civil Engineering, Varaždin, Croatia \\ 2 Department of Water Science and Engineering, Faculty of Agriculture, Ferdowsi University of Mashhad, \\ Mashhad, Iran; atena.pezeshki@mail.um.ac.ir (A.P.), sara.dadar@mail.um.ac (S.D.) \\ 3 University of Zagreb, Faculty of Geotechnical Engineering, Varaždin, Croatia; lucija.plantak@gfv.unizg.hr \\ (L.P.), nikola.kranjcic@gfv.unizg.hr (N.K.) \\ 4 University North, Department of Mechatronics, Varaždin, Croatia; damira.kecek@unin.hr \\ * Correspondence: bojan.durin@unin.hr; Tel.: +385-98-974-9716
}

\begin{abstract}
Due to the actual trends of the rising numbers of the population, as well as increasing of the living standard, wastewater treatment plants are exposed to the changes in the quantity and quality of input wastewater. Such changes the efficiency of the operational work of the wastewater treatment plant. There are many input and output parameters of the wastewater quality indicators (Biochemical Oxygen Demand through 5 days, Total Suspended Solids, Chemical Oxygen Demand, etc.), as well as input and output hydraulic parameters (flow of wastewater). There is a need to consider all of them and make a decision about the efficiency of the wastewater treatment plant. Among all procedures and methods, a multicriteria decision is one that could be applied in this research. The Paper will present the application of the Multi Composite Programming and Promethee method for the real case study of Parkandabad water treatment plant in Mashhad, Iran.
\end{abstract}

Keywords: wastewater; quality; quantity; efficiency; Multi Composite Programming; Promethee 